\title{
Does Legal Education have Undermining Effects on Law Students? Evaluating Changes in Motivation, Values, and Well-Being
}

\author{
Kennon M. Sheldon, Ph.D.* and \\ Lawrence S. Krieger, J.D. ${ }^{\dagger}$
}

We evaluated changes in subjective well-being (SWB), motivation, and values occurring over the law-student career. In study 1 , law students began with levels of SWB higher than a comparison sample of undergraduates, but by the end of the first year their SWB had plummeted. These changes were correlated with the sample-wide decreases in intrinsic motivation over the first year, and were also correlated with increases in appearance values and decreases in community service values. Those with the most intrinsic motivations attained the highest grades, but, ironically, high grades in turn predicted shifts in career preferences towards "lucrative" and higher-stress law careers, and away from "service"-oriented and potentially more satisfying law careers. The declines persisted over the second and third years of law school. In study 2 , the basic effects were replicated for a different sample of first-year students at a different law school. Implications for legal education and the legal profession are discussed. Copyright (C) 2004 John Wiley \& Sons, Ltd.

\section{INTRODUCTION}

\section{Problems in the Legal Profession}

The legal profession appears to be facing significant problems, manifested both in decreasing overall professionalism in the field, and in decreased health and

\footnotetext{
*Correspondence to: Kennon M. Sheldon, 112 McAlester Hall, Department of Psychological Sciences, University of Missouri, Columbia, Columbia, MO 65211, U.S.A. E-mail: SheldonK@missouri.edu ${ }^{\dagger}$ Florida State University College of Law.

The authors greatly appreciate the participation of the F.S.U. College of Law: the entering law school class of 2003; the Legal Writing Faculty for their assistance in administration of this study; and most particularly the support and openness to this research of Dean Donald Weidner and the Associate Deans of the College. We are particularly grateful for the untiring encouragement and assistance of Ann Iijima and Meg Daniel. Finally, we thank Paul Lebel, Laurie Morin, and Charles Senger for their comments on an earlier version of this draft.
} 
well-being among individual lawyers. For example, a Johns Hopkins study found lawyers to have the highest incidence of major depressive disorder among 104 occupational groups (Eaton, Anthony, Mandel, \& Garrison, 1990). Another major study found that two large samples of lawyers manifested clinical levels of depression, anxiety, phobia, and interpersonal sensitivity 5-15 times more commonly than the general population (Beck, Sales, \& Benjamin, 1995). Substance abuse is unduly frequent among lawyers (Allen, 1997; Beck et al., 1995; Benjamin, Darling, \& Sales, 1990; Drogen, 1991; Schiltz, 1999), and the suicide rate is exceptionally high as well (Burnett, 1998). Career dissatisfaction is widespread and is generally linked to the ascent of commercialism and the loss of character, service commitment, and professionalism among many lawyers (Joy, 1994; Kronman, 1993; Linowitz, 1994; Schiltz, 1999). The titles of some of these commentaries are revealing: The Lost Lawyer (Kronman, 1993), The Betrayed Profession (Linowitz, 1994), "On Being a Happy, Healthy, and Ethical Member of an Unhappy, Unhealthy, and Unethical Profession” (Schiltz, 1999), and At the Breaking Point (American Bar Association, 1991).

Research on law students echoes the findings among practicing lawyers, documenting similar problems of elevated emotional distress (Benjamin, Kaszniak, Sales, \& Shanfield, 1986; Dammeyer \& Nunez, 1999; Hess, 2002; Shanfield \& Benjamin, 1985) and substance abuse (AALS Special Committee, 1994). Although law students start out little different from students in other professional fields and from the general population (Benjamin et al., 1986), soon after law school commences they report large increases in psychiatric symptomology, such as anxiety, depression, hostility, and paranoia (Benjamin et al., 1986; Dammeyer \& Nunez, 1999; Shanfield \& Benjamin, 1985). These declines continue into the second and third year of law school, and may even persist into their subsequent law careers (Beck et al., 1995; Benjamin et al., 1986). Also, the symptoms apparently reflect more than mere hard work, as law students soon evidence poorer mental health than medical students, another difficult professional program (Dammeyer \& Nunez, 1999; Shanfield \& Benjamin, 1985).

Many researchers and commentators have proposed that legal education may be the common source of some of the problems among both students and lawyers. Potential negative aspects of legal education include excessive workloads, stress, and competition for academic superiority (Culp, 1994; Fines, 1997; Glesner, 1991; Halpern, 1982; Hess, 2002; Krieger, 1998); institutional emphasis on comparative grading, status-seeking placement practices, and other hierarchical markers of worth (Daicoff, 1997; Fines, 1997; Granfield, 1992; Kennedy, 1982; Krieger, 1998); lack of clear and timely feedback (Granfield, 1992; Hess, 2002; Kennedy, 1982); excessive faculty emphasis on analysis and linear thinking, causing loss of connection with feelings, personal morals, values, and sense of self (Coquillette, 1994; Culp, 1994; Granfield, 1992; Hess, 2002; Krieger, 1998; Meltsner, 1983; Mixon \& Shuwerk, 1995; Sells, 1994); teaching practices that are isolating or intimidating, and content that is excessively abstract or unrelated to the actual practice of law (Glesner, 1991; Granfield, 1992; Kronman, 1993; Roach, 1994; Sells, 1994; Taylor, 1975; Watson, 1968); and conceptions of law that suppress moral reasoning and creativity (Culp, 1994; Hess, 2002; Janoff, 1991; Stover \& Erlanger, 1989).

Notably, there is little empirical research that directly or causally links such factors to the observed symptoms. And indeed, there has been very little theory-guided 
research at all, concerning these issues and problems (Dammeyer \& Nunez, 1999). However, based largely on the theories of Maslow (1970), Krieger (1998) recently proposed that the dominant beliefs and practices in legal education thwart natural human needs for growth, personality integration, and internally based motivation, potentially explaining many of the negatives noted in legal education, and later, in the legal profession. Specifically, Krieger argued that the intense pressures and competitive success norms at most law schools begin a process that reorients students away from positive personal values and towards more superficial rewards and image-based values, leading to a loss of self-esteem, life satisfaction, and wellbeing. Based on this argument, Krieger called for longitudinal research examining correlated changes in law student well-being, motivation and values, and need satisfaction, to perhaps identify important root causes of the many problems in the legal profession.

In the current study we attempted to answer this call, basing our work on the self-determination theory of optimal motivation and human thriving (SDT; Deci \& Ryan, 1985, 1991, 2000). This theory, and its 30-year empirical research tradition, focuses on the contextual and personality factors that cause positive and negative motivation, with corresponding positive and negative performance and subjective well-being (SWB) outcomes. Because the theoretical focus of SDT is related to many of the above propositions and critiques, we hoped that applying this theory might shed new light on the law school conundrum, as well as perhaps suggesting concrete ways to ameliorate the various problems. Below we provide a brief overview of SDT.

\section{Self-Determination Theory}

SDT began with the concept of "intrinsic motivation," in which a person engages in an activity because she finds it interesting and enjoyable. Early experimental research (Deci, 1972, 1975) showed that controlling or coercive authorities and environmental contexts tend to undermine intrinsic motivation, by thwarting people's inherent need to be autonomous and self-regulating. Although performance pressures, extrinsic rewards and enticements, and desires to impress others may produce positive performance to some extent, these factors tend to work against persistence, enjoyment, creativity, and integration in the long run (see Deci \& Ryan, 1985, or Deci, Koestner, \& Ryan, 1999, for a review).

In the late 1980s SDT researchers began to focus on extrinsic motivation, i.e. activity undertaken as a means to an end, rather than as an end in itself (Ryan \& Connell, 1989). This more recent work demonstrates that extrinsic motivations are not necessarily detrimental, provided that they have been internalized-that is, provided the person identifies with the rationale and value behind the behavior. In this case people still feel that the behavior is their choice, even if they do not enjoy it. However, when people feel that external pressures or internal compulsions dictate their instrumental behavior, then extrinsic motivations can have problematic effects (Deci \& Ryan, 2000). SDT now specifies three basic types of extrinsic motivationexternal, introjected, and identified - that vary in their degree of internalization by the individual. For example, a person may pay her taxes primarily to avoid fines or imprisonment (an external, non-internalized motive), primarily to forestall feelings 
of guilt or self-recrimination (an introjected, partially internalized motive), or primarily to support the intended goal of the taxes, of providing for the common good (an identified, fully internalized motive).

Importantly, research has found that external and introjected motivations are typically associated with negative SWB and task performance, whereas identified and intrinsic motivations are associated with positive SWB and performance (Deci \& Ryan, 1991, 2000; Sheldon, Williams, \& Joiner, 2003). In short, SDT research has found that "why" a person acts - whether he perceives his behavior as motivated by his own interests, values, and beliefs, or whether he instead perceives that external or self-alien factors control his behavior-has significant consequences for his/her satisfaction and performance.

In addition to considering why people act, in the 1990s SDT began to focus on another important motivational factor: what people seek through their actions, i.e., the content of their goals and values. Do people pursue extrinsic goals and values, such as money, image, and fame, or do they pursue intrinsic goals and values, such as intimacy, community, and personal growth (Kasser \& Ryan, 1993, 1996)? Factor-analytic research has supported the conceptual distinction between intrinsic and extrinsic values (Kasser \& Ryan, 1996; Sheldon, Arndt, \& Houser-Marko 2003), and has also established that persons who strongly endorse extrinsic values evidence diminished SWB and adjustment (Deci \& Ryan, 2000; importantly, these data indicate that there is no negative effect from strongly valuing money, popularity and appearance per se, provided that the person does not ascribe them more importance than the intrinsic values listed above). Deci and Ryan (2000) argue that the negative association between strong extrinsic valuing and SWB occurs because extrinsic values are less directly satisfying of fundamental psychological needs, and are more often associated with frustration and irritation. Research has also shown that the extrinsic value (i.e. content) effects are not reducible to the fact that such values are often pursued for controlled or non-autonomous reasons (i.e., they are not mere motive effects; Ryan, Sheldon, Kasser, \& Deci, 1996; Sheldon, Ryan, Deci, \& Kasser, in press); that is, the two types of construct have additive, independent effects. In short, much SDT research shows that both what people do, and the reasons why they do it, can make a difference for SWB.

\section{Applying SDT to Understand Negative Changes in Law School}

These concepts are important because they provide one potential way of understanding why law students' SWB might decline over time. If students begin law school with intrinsic motivations and internalized extrinsic motivations (striving for reasons of interest and/or personal conviction) but then move towards noninternalized or "controlled" motivations (striving for reasons of external coercion, fear, or guilt), this could produce a loss of satisfaction and engagement, and ultimately contribute to the many observed problems in the legal profession. Also, if students begin with intrinsic value contents (such as helping others or personal growth) but move towards extrinsic values (such as impressing others, or gaining status and affluence), this would also help explain the negative trends in SWB, as well as perhaps explaining the negative stereotypes (i.e. shallowness, greed, hypercompetitiveness) commonly associated with lawyers. 
We conducted two studies to evaluate these propositions. Study 1, the primary study, followed a sample of students at Florida State University (law school 1/LS1) during their three years of law school. Study 2, the secondary study, was conducted to test the observed first-year effects in a second law school (law school 2/LS2).

\section{STUDY 1}

\section{Study Hypotheses}

\section{Three Preliminary Hypotheses}

To lay the groundwork for our primary hypotheses, we first ventured three preliminary hypotheses. First, we evaluated the initial SWB, motivation, and values of the students at law school 1. Consistent with earlier studies of law students (Benjamin et al., 1986, 1990), we hypothesized that Law students would be no lower in time 1 intrinsic values or SWB than a comparison sample of advanced undergraduates. This would indicate that any problems arising among the law students did not predate their matriculation. An advanced undergraduate sample appeared to be an appropriate control for the law student sample, given that most law students have only recently completed their undergraduate education.

Consistent with earlier SDT studies, our second preliminary hypothesis was that In the law student sample, time 1 autonomous motivations and intrinsic values would be positively associated with time 1 SWB, and, conversely, controlled motivations and extrinsic values would be negatively associated with time 1 SWB (Deci \& Ryan, 2000; Sheldon \& Elliot, 1999; Sheldon \& Kasser, 1995, 1998, 2001). Support for this cross-sectional hypothesis would establish a connection between the law student sample and past SDT research samples, and help set the stage for the longitudinal motivational analyses to follow.

Our third preliminary hypothesis, derived from past studies of law students (Benjamin et al., 1986), was that Students would show a large decline in SWB over the course of their first year, including both reductions in positive and increases in negative $S W B$. Finding support for this hypothesis would establish the connection between the current data and prior studies of law student well-being, and further help set the stage for the motivational analyses to follow.

\section{Two Primary Hypotheses}

Consistent with commentaries on the competitive and perhaps undermining pressures and norms of law school, our first primary hypothesis was that Participants would experience declining autonomous motivation and increasing controlled motivation (the "why" of motivation) over the first year, as well as declining intrinsic values and increasing extrinsic values (the "what" of motivation). Finding support for these hypotheses would buttress the notion that some aspects of law school may be detrimental to students.

In addition, we hypothesized that Negative changes in motivations and values would be correlated with negative changes in SWB. In other words, motivation changes could perhaps account in part for the well-being changes, and also perhaps account for 
some of the later problems among practicing lawyers. Of course, such associations could not prove causality, but they would at least be consistent with our notion that changes in motivation and values help to produce law students' declining well-being.

\section{Supplementary Issues and Hypotheses}

We also examined several supplementary issues, which were of considerable interest but not of primary importance for this study. As a first issue, we examined whether any changes in SWB, motives, or values occurring during the first year would persist into the second and third years. To evaluate this we conducted follow-up surveys in November of the second year and November of the third year. We made no predictions regarding this issue, because, although our theoretical perspective suggests that the problems might continue to worsen over time, contemporary theories of longitudinal well-being suggest that people typically return to their starting point after their well-being is altered, that is, they move back towards their genetically determined "set point" for well-being (Diener \& Lucas, 1999; Lykken \& Tellegen, 1996). Such hedonic adaptation may limit or reverse any negative changes in the current sample.

As a second supplementary issue, we examined the associations of positive motivations and values with graded performance in law school. Consistent with past SDT research concerning the positive performance effects of internal motivation, we hypothesized that Self-determined motivations and intrinsic values would predict graded performance (Deci \& Ryan, 2000; see also Fines, 1997). According to SDT, those who enjoy and identify with their studies, and who pursue them with intrinsic values in mind, thereby acquire the motivational resources to achieve superior performance.

As a third supplementary issue, we examined career preferences among the law students. We distinguished between "service-oriented" careers, such as public defender, public agency lawyer, and counsel for nonprofit organization; "moneyoriented" careers, such as large firm, plaintiff's tort/medical malpractice, and corporate/commercial practice; and "other" careers, such as general practice or small firm practice. We hypothesized that Law students in general would tend to shift towards money-oriented career preferences (Astin, 1984; Granfield, 1992; Stover \& Erlanger, 1989). Finally, we also hypothesized that Students achieving higher grades would evidence larger measured shifts towards money-oriented career preferences, as emerging lucrative career possibilities may tempt high-performing students away from their initial, more altruistic preferences. These two hypotheses were based on the assumption that law school culture promotes greater adoption of material- and image-based values, especially in those who thrive within that culture (Krieger, 1998).

\section{METHODS}

\section{Sample and Procedure}

\section{Law Student Sample}

The primary participants were first-year law students at Florida State University, who began law school in August 2000. As an incentive, students were promised a 
personalized report regarding their own scores, to be given at the end of the study. Two hundred and thirty-five out of 245 matriculating students completed the initial "Attitudes and values" survey. Of these participants, 125 were men and 110 women; 154 were 25 years old or less, 54 were in the 26-30 range, 14 were in the 31-35 range, 8 were in the 36-40 range, 11 were in the $41-45$ range, and 4 were older than 45 . Seventy-six participants reported having had some previous career, and of these 26 had had two or more previous careers. Seventy-six percent of the matriculating class were Caucasian, 10\% were Hispanic or Latino, 23\% were African-American, 4\% were Asian-American, and 1\% were "Other."

Of the original sample, 193 completed the second survey, in March 2001. ${ }^{1}$ One hundred and thirty-six students completed a third survey, in November 2001, and one hundred and thirty-four students completed a fourth survey, in November 2002. We will discuss the possible effects of sample attrition in the results section, below.

\section{Procedure}

Participants completed the time 1 questionnaire during a group orientation meeting on their first day of law school, in August 2000, after first creating a unique code to protect their confidentiality. Participants were given the time 2 questionnaire in late March 2001, during class meetings in seven different sections of the same course. Most time 2 surveys were completed in class, although some students who did not have sufficient class time completed and turned in the survey later. The time 3 and time 4 questionnaires were left in participants' mailboxes in early November 2001 and 2002, and completed questionnaires were returned to the study coordinator over a subsequent two-week period. Follow-up emails and phone-calls were made for the time 2, time 3, and time 4 questionnaires, in order to maximize return rates. A monetary incentive was offered for the time 4 survey, such that respondents would be entered into a lottery with three chances to win $\$ 100$.

\section{Comparison Time 1 Sample}

The undergraduate comparison sample consisted of 236 members of an upper division psychology class at the University of Missouri, who were administered a survey in August 2001. Again, we viewed this sample as quite representative of participants in prior published work concerning SDT and SWB (see Deci \& Ryan, 2000, for a review). These participants were administered three of the four SWB measures, and also the values measure (described below).

\section{Measures}

\section{Subjective Well-Being}

Our SWB analysis focused on three central constructs within the SWB literature: positive affect, negative affect, and life satisfaction (Diener \& Lucas, 1999). Positive

\footnotetext{
${ }^{1}$ Not all time 2 analyses have the full $n$ of 193, as there were scattered missing data for some variables.
} 
and negative affect refer to happy and unhappy mood states, respectively, whereas life satisfaction refers to global cognitive judgments about one's life as a whole. Together these cover the three most important facets of SWB, according to many contemporary researchers (Diener, 1984, 1994; Diener \& Lucas, 1999; Sheldon \& Elliot, 1999; Sheldon \& Kasser, 1998). Mood was measured with the Positive Affect Negative Affect Schedule (Watson, Tellegen, \& Clark, 1988). In each survey participants were asked to rate how much, during the last month or so, they had experienced each of 20 mood adjectives (10 positives such as "enthusiastic" and "proud," and 10 negatives such as "anxious" and "frustrated"), using a 1 (not at all) to 5 (very much) scale. Life satisfaction was measured via the Satisfaction with Life Scale (SWLS; Diener, Emmons, Larsen, \& Griffin, 1985). Participants rated how well five statements characterized their life during the past month (such as "the conditions of my life are excellent"), using the same scale as above. These measures were administered at all four time periods.

To round out the assessment we also measured physical health at times 1,2 , and 3 by asking participants to rate 18 symptoms (based on Emmons, 1991), such as "runny nose/sore throat," "insomnia," and "headaches," again using the same time frame and scale as above. Finally, we measured depression (at times 1 and 2 only), using the Beck Depression Inventory (Beck, 1967), in order to evaluate the consistency of our results with previous studies of law students focusing on psychiatric symptoms (Benjamin et al., 1986).

Positive affect, negative affect, life-satisfaction, depression, and physical symptom scores were created for each participant for each administration, by averaging the appropriate items. As in past research we also created an aggregate SWB score for each participant at each time, by adding positive affect and life satisfaction, and subtracting negative affect (Diener \& Lucas, 1999; Sheldon \& Elliot, 1999; Sheldon $\&$ Kasser, 1998). Alpha coefficients ranged between 0.84 and 0.92 for these scales.

\section{Motivation and Values}

To assess the "why" of motivation (i.e., autonomous versus controlled reasons for acting), we began with an idiographic personal goal assessment (Emmons, 1999; Little, 1993; Sheldon \& Elliot, 1999). Specifically, in the time 1 survey participants were asked to write down five law school goals, i.e. "things that you will be trying to accomplish in the coming year." Although examples of goals were provided, participants were instructed to write down anything they wanted, including goals specific to law school, and also goals in other areas of their lives.

After listing their personal goals, participants were asked to rate why they were pursuing each goal, in terms of each of four different reasons. As described in the introduction, two of these motivations are conceptualized as autonomous by SDT: intrinsic ("because of the enjoyment and stimulation that this activity provides you") and identified ("because you really believe it is an important goal to have"). In these cases individuals fully endorse, and feel that they are the cause of, their own behavior. The other two reasons are conceptualized as non-autonomous, or controlled, by SDT: external ("because others want you to or think you should"), and introjected ("because you would feel ashamed, guilty, or anxious if you didn't"). In these cases individuals typically feel that they do not fully cause their own behavior. 
All goals were rated using a 1 (not at all for this reason) to 5 (very much for this reason) scale, and we averaged across the five goals, for each reason.

Below we present results for each of the four types of motivation separately, and also for a relative self-determination index derived by subtracting external and introjected scores from intrinsic and identified scores. The latter variable has been shown by past research to be associated with positive SWB (Sheldon \& Kasser, 1995, 1998; Sheldon \& Elliot, 1999). Because of time and space constraints on the survey administration, the goal measures were given only at time 1 and time 2 . Alpha coefficients ranged from 0.64 to 0.86 for these scales.

To assess the "what" of motivation, we employed the Aspirations Index (Kasser \& Ryan, 1993, 1996; Sheldon \& McGregor, 2000; Sheldon, Sheldon, \& Osbaldiston, 2000). This 30-item scale has six facets: three extrinsic values (financial success, appealing appearance, and social popularity), and three intrinsic values (emotional intimacy, community contribution, and personal growth). Participants are asked how important it is that various future states come to pass (e.g. "I will have many expensive possessions," a financial success item, and "I will help others improve their lives," a community contribution item), using a 1 (not at all important) to 5 (very important) scale. Below we present results for each of the six values separately, and also present results for an aggregate "Intrinsic value orientation" measure, derived by summing the three intrinsic scores and subtracting the three extrinsic scores. This summary variable indexes the relative importance of intrinsic compared to extrinsic values, and has also been shown by past research to be positively correlated with SWB and psychosocial adjustment (see Deci \& Ryan, 2000, for a review). The Aspirations Index was given at all four times. Alpha coefficients ranged between 0.85 and 0.86 over these four administrations.

\section{Other Measures}

In the time 1 survey, participants were also asked to provide their LSAT scores. These scores, which ranged from 137 to 171 with a mean of 155 , are treated as a continuous variable below. In the time 2 and time 3 surveys participants were asked to indicate their first and second semester grade-point averages (coded numerically and by letter grades, which ranged from $\mathrm{F}$ to $\mathrm{A}+$, with a median of $\mathrm{C}+$ ). In the results below, these variables are also treated as continuous measures, such that a higher score represents a higher GPA.

Finally, participants were asked to indicate their career preferences at time 1 and time 2, by indicating their first, second, and third choice preferences from a list of 15 careers. As noted above, five of the 15 career preferences were typed as "service" oriented, four were typed as "money" oriented, and the other seven were typed as "other" (see the appendix a for a list). We asked participants to make their selections with the assumption that "any college loan obligations you might have would be handled by your choice." This wording sought to ensure that any reported career orientation changes are not reducible to student concerns over coping with debt but rather reflect genuine preferences-our primary interest, given our focus on intrinsic motivation and on personality change. We computed scores for both money- and service-oriented career preferences, for each participant, by counting how many times they chose exemplars of each of the two types, at each time period. 
These four scores were also treated as continuous variables. Supporting the validity of these measures, relative intrinsic value orientation at time 1 was correlated $r=0.30 \quad(p<0.01)$ with service career orientation at time 1 , and $r=-0.28$ $(p<0.01)$ with money career orientation at time 1 .

\title{
RESULTS
}

\begin{abstract}
Attrition
First we focused on the law student sample, examining whether those who dropped out of the study after time 1 differed initially from those who completed the study. Independent sample $t$-tests were conducted on the five time $1 \mathrm{SWB}$ variables, the relative self-determination variable, and the intrinsic value orientation variable, as well as on LSAT score and first semester GPA. The first tests compared those who did not complete time $2(n=42)$ with those who completed time $2(n=193)$. One of these differences was significant, in that those who remained in the study at time 2 evidenced somewhat greater time 1 intrinsic value orientation than those who dropped out $(M=5.14$ versus $M=4.22, t(233)=2.11, p<0.05)$. Next, we conducted eight of the above nine analyses comparing the original participants who did not complete time $3(n=99)$ with those who completed time 3 ( $n=136$; selfdetermination was not assessed at time 3). Again, one difference was significant in that those who remained in the study at time 3 evidenced somewhat greater time 1 intrinsic value orientation than the initial sample $(M=5.37$ versus $M=4.50$, $t(233)=2.84, p<0.01)$. Next, we conducted seven of the nine analyses comparing the original participants who did not complete time $4(n=101)$ with those who completed time $4(n=134$; self-determination and symptoms were not assessed at time 4). No significant differences were found. Notably, the fact that only two out of 24 differences were significant suggests that there was little systematic difference between the time 1 sample and the time 2, time 3, and time 4 sub-samples due to attrition. Thus, we attempted to maximize power by using all available information in the hypothesis tests, resulting in somewhat varying $n$ s at different times.
\end{abstract}

\section{Preliminary Hypotheses}

\section{Comparing Law Students and Undergraduates at Time 1}

Table 1 provides means for all of the time 1 variables, for both samples. Table 1 also contains the results of independent sample $t$-tests, comparing the law student sample with the undergraduate sample.

Compared with the Missouri undergraduates, the entering law students evidenced higher positive affect and higher life satisfaction, as well as higher aggregate SWB (all three $p$ s $<0.01$ ). There was no significant difference in negative affect. On the values measures, the law students also evidenced more intrinsic values overall than the undergraduates $(p<0.01)$, largely because they gave less endorsement to appealing appearance and social popularity values (both $p s<0.01$ ). 
Table 1. Study 1, time 1: Comparing the law school sample with the undergraduate sample

\begin{tabular}{lll}
\hline & \multicolumn{2}{c}{ Sample } \\
\cline { 2 - 3 } Variables & LS1 law students & UM undergraduates \\
\hline Well-being & & $4.28^{*}$ \\
Aggregate SWB & 4.87 & $3.60^{*}$ \\
Positive affect & 3.79 & 2.55 \\
Negative affect & 2.43 & $3.24^{*}$ \\
Life satisfaction & 3.51 & - \\
Symptoms & 1.93 & $4.68^{*}$ \\
Values & & 3.16 \\
Relative intrinsic value orientation & 4.99 & $2.67 *$ \\
Financial success & 3.32 & $2.69 *$ \\
Appealing appearance & 2.37 & 4.01 \\
Social popularity & 2.38 & 4.49 \\
Community contribution & 3.89 & 4.71 \\
Personal growth & 4.50 & \\
Emotional intimacy & 4.66 & \\
\hline
\end{tabular}

Significance tests compare the differences between the undergraduate sample and the law sample. $* p<0.01$.

The most important thing to take from these analyses is that the law students appeared quite happy and healthy at the beginning of their career, with relatively intrinsic and prosocial values. This suggests, consistent with earlier research (Benjamin et al., 1986), that any later distress among the law students is not an effect of pre-existing distress or problematic personality traits. To summarize, our first preliminary hypothesis, that incoming law students start out with neither lower SWB nor especially extrinsic values, received good support; in fact, the law students appeared to be happier and to have more intrinsic values.

\section{Examining Associations of Time 1 Motivation and Values with Time 1 SWB}

The remaining analyses focus exclusively on the law student sample. Our second preliminary hypothesis stated that self-determined motivation and intrinsic value orientation at time 1 would be associated with time 1 SWB, establishing the consistency of this sample with prior SDT samples. Table 2 contains these results.

Table 2. Study 1: Correlations between self-determined motivation, intrinsic value orientation, and well-being at time 1 in the law school sample

\begin{tabular}{lccccc}
\hline & \multicolumn{5}{c}{ Well-being variables } \\
\cline { 2 - 5 } Predictors & $\begin{array}{c}\text { Aggregate } \\
\text { SWB }\end{array}$ & $\begin{array}{c}\text { Positive } \\
\text { affect }\end{array}$ & $\begin{array}{c}\text { Negative } \\
\text { affect }\end{array}$ & $\begin{array}{c}\text { Life } \\
\text { satisfaction }\end{array}$ & $\begin{array}{c}\text { Physical } \\
\text { symptoms }\end{array}$ \\
\hline $\begin{array}{l}\text { Relative self- } \\
\text { determination }\end{array}$ & $0.31^{*}$ & $0.32^{*}$ & $-0.11^{+}$ & $0.36^{*}$ & -0.05 \\
$\begin{array}{l}\text { Relative intrinsic } \\
\text { value orientation }\end{array}$ & $0.29 *$ & $0.25^{*}$ & $-0.17^{*}$ & $0.23^{*}$ & -0.03 \\
\hline
\end{tabular}

${ }^{+} p<0.10 ; * p<0.01$. 
As can be seen, the hypothesis was well supported in the case of positive affect, negative affect, life satisfaction, and aggregate SWB. The associations of time 1 selfdetermined motivation and intrinsic value orientation with time 1 physical symptomology were not significant, although they were in the predicted direction.

\section{Examining Changes in SWB from Time 1 to Time 2}

Next we turned to our third preliminary hypothesis, concerning changes in SWB during the first year. A series of matched-pair $t$-tests were conducted, comparing the time 1 and the corresponding time 2 variables. The means for these comparisons can be found in Table 3. The SWB analyses showed that participants experienced large reductions in positive affect, life satisfaction, and overall SWB, and large increases in negative affect, depression, and physical symptoms (all $p s<0.01$ ). Notably, regression product-term analyses using dummy variables to represent demographic factors revealed that these main effects were not moderated by students' gender, ethnicity, age, career experience, or first-semester GPA - that is, they were the same for students of all demographic types. These SWB declines establish commensurability between the current study and the studies of previous investigators of law-student well-being (see Beck et al., 1995, for a review), and set the stage for the question of whether law students also change in their motivation and values over the first year.

Table 3. Study 1: Changes in well-being, values, and motivation from August 2000 to March 2001

\begin{tabular}{lrrr}
\hline & \multicolumn{2}{c}{ Time } & \\
\cline { 2 - 3 } Variables & August & March & p-level for the difference \\
\hline Well-being & & & \\
$\quad$ Aggregate SWB & 4.85 & 3.88 & $<0.01$ \\
Positive affect & 3.79 & 3.29 & $<0.01$ \\
Negative affect & 2.47 & 2.66 & $<0.01$ \\
Life satisfaction & 3.53 & 3.25 & $<0.01$ \\
Symptoms & 1.95 & 2.21 & $<0.01$ \\
Beck depression & 6.12 & 7.94 & $<0.01$ \\
Values & & & \\
Relative intrinsic value orientation & 5.14 & 4.75 & $<0.01$ \\
Financial success (E) & 3.29 & 3.30 & 0.82 \\
Appealing appearance (E) & 2.31 & 2.47 & $<0.01$ \\
Social popularity (E) & 2.31 & 2.30 & $<0.01$ \\
Community contribution (I) & 3.87 & 3.74 & 0.18 \\
Personal growth (I) & 4.49 & 4.44 & 0.11 \\
Emotional intimacy (I) & 4.69 & 4.64 & \\
Motivation for goals & & & $<0.01$ \\
Relative self-determination & 4.27 & 3.65 & $<0.01$ \\
External motivation (C) & 1.57 & 1.76 & 0.64 \\
Introjected motivation (C) & 2.38 & 2.34 & 0.12 \\
Identified motivation (A) & 4.29 & 4.17 & $<0.01$ \\
Intrinsic motivation (A) & 3.93 & 3.57 & \\
\hline
\end{tabular}

$\mathrm{E}=$ extrinsic value, $\mathrm{I}=$ intrinsic value, $\mathrm{C}=$ controlled motivation, $\mathrm{A}=$ autonomous motivation. 


\section{Primary Hypotheses}

\section{Examining Changes in Motivation and Values from Time 1 to Time 2}

Our first primary hypothesis stated that law students would evidence negative changes in motivation and values during the first year. A paired-sample $t$-test indicated that participants indeed experienced reduced overall self-determination from the beginning to the end of their first year $(p<0.01)$. In the language of SDT, this suggests a classic "undermining" effect, in which initial positive motivations are eroded or usurped (Deci \& Ryan, 1985). SDT has typically focused on controlling and coercive environments as the cause of such effects (Deci \& Ryan, 1985, 1991, 2000), and thus this finding is consistent with our suggestion that law school may represent such an environment.

Focusing on each motivational domain separately, students experienced increased external motivation from August to March and decreased intrinsic motivation during that time (both $p s<0.001$ ). There were no significant changes in introjected or identified motivation. Again, as with the SWB declines, the changing motivation effects were independent of students' gender, ethnicity, or age. In other words, students of all demographic types came to feel that pursuit of their law-school goals was less interesting or enjoyable, and was more controlled by others' desires and dictates.

Next, we examined changes in the relative intrinsic value orientation measure, also using a paired-sample $t$-test. This analysis indicated that participants became significantly less endorsing of intrinsic values relative to extrinsic values overall, during the course of the first year $(p<0.01)$. When we examined the six value domains separately, a significant increase in valuing of "appealing appearance" emerged (an extrinsic value), as did a significant decrease in the valuing of "community contribution" (an intrinsic value; both $p s<0.01$; changes were not significant for the other four value subscales). Again, the effects were not moderated by gender, ethnicity, or age.

\section{Examining Correlations Between Changes in Motivation/Values and Changes in SWB}

Are the declines in self-determined motivation and intrinsic valuing associated with the declines in well-being? To examine this question we computed a change score for each SWB variable, and also for the self-determination and intrinsic value orientation variables, by subtracting the time 1 score from the corresponding time 2 score. Then we correlated the change scores.

Table 4 contains the results. As can be seen, declines in self-determination (the "why" of motivation, as specified by SDT) were significantly associated with increases in negative affect and physical symptoms, and with decreases in positive affect and aggregate SWB. Declines in intrinsic value orientation (the "what" of motivation, as specified by SDT) were significantly associated with decreases in positive affect, life satisfaction, and aggregate SWB. Although causality cannot be established via these correlational data, the consistency of the findings with our theoretical assumptions is noteworthy. 
Table 4. Study 1: Correlations between changes in motivations/values and changes in well-being

\begin{tabular}{|c|c|c|c|c|c|}
\hline & \multicolumn{5}{|c|}{ Decrease in well-being } \\
\hline & $\begin{array}{l}\text { Aggregate } \\
\text { SWB }\end{array}$ & $\begin{array}{l}\text { Positive } \\
\text { affect }\end{array}$ & $\begin{array}{l}\text { Negative } \\
\text { affect }\end{array}$ & $\begin{array}{c}\text { Life } \\
\text { satisfaction }\end{array}$ & $\begin{array}{l}\text { Physical } \\
\text { symptoms }\end{array}$ \\
\hline $\begin{array}{l}\text { Decreases in relative } \\
\text { intrinsic value orientation }\end{array}$ & $0.17 *$ & $0.15^{*}$ & -0.07 & $0.15^{*}$ & -0.04 \\
\hline $\begin{array}{l}\text { Decreases in relative } \\
\text { self-determined motivation }\end{array}$ & $0.19 * *$ & $0.13^{+}$ & $-0.18^{*}$ & 0.10 & $-0.26^{* *}$ \\
\hline
\end{tabular}

${ }^{+} p<0.010 ; * p<0.05 ; * * p<0.01$.

\section{Supplementary Analyses}

\section{Examining Changes from Time 2 to Time 3, and from Time 3 to Time 4}

Next, we turned to analysis of the supplementary time 3 and time 4 data, gathered in November of the second and third years of law school. We asked two basic questions of these data: first, does students' $S W B$ "rebound" from time 2 to time 3, or from time 3 to time 4 ? That is, might the SWB changes simply be an artifact of a first-year adjustment process, after which students regain their former levels? Second, do student's values rebound or return to their former levels? If either is the case, then concern over the results presented above might be mitigated. Again, we ventured no hypotheses concerning these issues.

Specifically, we compared the mean levels of aggregate SWB and relative intrinsic value orientation of those with data at both time 2 and time $3(n=132)$, and those with data at both time 3 and time $4(n=102)$. No significant effects were found for any of these four analyses. In other words, the declines in SWB and intrinsic valuing observed between August 2000 and March 2001 remained constant, in that the reduced time 2 levels were unchanged in both November 2001 and November 2002.

As a secondary analysis, we examined changes in the six individual value domains from time 2 to time 3, and from time 3 to time 4 . Interestingly, students declined significantly in five out of the six values from time 2 to time 3 (excluding appearance values); the reason there was no change in the relative intrinsic orientation score was because the decreases in extrinsic and intrinsic values tended to "cancel out" within this composite difference variable. These data suggest that rather than moving further towards extrinsic and away from intrinsic values, as they did from time 1 to time 2, students instead reported less valuing of all kinds at time 3 . When we compared time 3 with time 4 , no significant changes were observed in any of the individual value domains. In other words, the reduction in all types of valuing found between time 2 and time 3 remained in place at time 4.

\section{Predicting Law-School GPA}

Our first supplementary hypothesis was that self-determined motivation and intrinsic values would both predict graded performance during the first year. We 
created summary self-determined motivation and intrinsic values scores, by averaging the time 1 and time 2 measures. We also computed an aggregate GPA measure by averaging each student's first and second semester GPA scores. We reasoned that tests involving these aggregated measures, based on two observations per participant, would provide the most reliable estimate of the true associations.

As hypothesized, at the bi-variate level, LSAT score $(r=0.24, p<0.01)$, selfdetermined motivation $(r=0.20, p<0.05)$, and intrinsic value orientation $(r=0.18$, $p<0.05)$ all had significant positive associations with GPA. To evaluate the relative strength of the predictors we entered all three into a simultaneous regression predicting GPA. In this analysis LSAT emerged as significant $(\beta=0.24, p<0.01)$, selfdetermined motivation was marginally significant $(\beta=0.17, p=0.07)$, and intrinsic values were non-significant $(\beta=0.07)$. In a follow-up analysis, both LSAT and a "positive motivation" variable derived by averaging the self-determination and intrinsic value orientation variables were significant simultaneous predictors of GPA $(\beta=0.23$ and $\beta=0.18$, both $p$ s $<0.05)$.

\section{Examining Changes in Career Choices}

Next we examined our two final supplementary hypotheses, that students as a whole would move towards money-oriented careers during the first year, and also that students achieving higher grades would evidence more of this trend. Interestingly, however, from time 1 to time 2, students as a whole moved away from the careers we felt most clearly reflected a "money" orientation $(M s=1.23$ and 1.05 , respectively, $t(188)=3.13, p<0.01)$. There were no aggregate changes in service career preferences from time 1 to time $2(M s=0.68$ and $0.67, n s)$. In short, our second supplementary hypothesis, that students would move towards money and away from service career preferences, was not supported by the data. Possible reasons for this are considered in the general discussion.

Next, we tested our third supplementary hypothesis, that students attaining high grades would shift towards money-oriented careers over the first year. We first computed difference scores for both service and money-oriented careers by subtracting the time 1 from the time 2 scores. We then correlated first semester GPA with these two difference scores. Consistent with the hypothesis, GPA correlated positively with change towards money-oriented careers $(r=0.20, p<0.01)$ and negatively with change towards service-oriented careers $(r=-23, p<0.01) .^{2}$

\section{BRIEF DISCUSSION}

The above results demonstrate, consistent with past research, that law students experience declining happiness and well-being during their first year in law school. Supporting our first primary hypothesis, students also reported a shift towards more extrinsic values over time (negative change in the "what" of motivation), and a reduction in their sense of self-determination for their law-school goals (negative

\footnotetext{
${ }^{2}$ To evaluate the effects of first-semester GPA we conducted a separate regression analysis for each SWB variable, predicting the time 2 score from the time 1 score and from first-semester GPA. In no cases was the GPA effect significant.
} 
change in the "why" of motivation). Supporting our second primary hypothesis, the changes in motivation and values were correlated with the changes in well-being. Thus, these data may begin to supply an explanation of the well-being changes documented by earlier research (Benjamin et al., 1986).

\section{STUDY 2}

One limitation of study 1 is that the results came from a single law school, located in a particular part of the country. We believe that this law school is typical of many other public law schools, given its size, demographics, and course of study. ${ }^{3}$ However, we recognize that the results might not generalize to other law schools, located in different parts of the country, with different institutional cultures or grading standards. Therefore, in study 2 we assessed the entering class at a second law school, at both the beginning of the first year and near the end of the first year. Many of the same measures were administered, to establish the replicability of the basic pattern of first-year effects. We sought to determine (i) whether declines in $S W B$, motivation, and values would be observed in this sample, as in the LS1 sample, and (ii) whether negative changes in motivation and values would be associated with negative changes in SWB, as in the LS1 sample.

\section{METHOD}

\section{Sample and Procedure}

The sample consisted of first-year law students from a law school that differed from LS1 in significant respects. Law school 2 (LS2) is a privately funded college located in a major urban area in the American Midwest. It is much larger than LS1 (approximate enrollments are 610 and 1,000, respectively); LS1 permits only fulltime law study, whereas LS2, like many urban law schools, has a significant parttime enrollment (approximately $40 \%$ of LS2 students enroll for 8-11 credits in the evening session). In addition, and unlike LS1, LS2 requires first year students to attend several offerings in its Perspectives on the Legal Profession program, which includes topics of well-being, depression, substance abuse, and professional values. Finally, LS2 has no curve for grades, whereas LS1 has a mandatory curve that

\footnotetext{
${ }^{3}$ The faculty mission emphasizes scholarly writing, teaching, and service as a third stated objective. Students are sufficiently diverse in terms of age, gender, race, and ethnicity, and are selected primarily for high undergraduate grades and LSAT scores. Professors are primarily alumni of elite law schools who evidenced early scholarly potential (i.e. previous publications, exceptional academic records, and law review editorships); previous law practice experience is not a criterion for hiring professors. The first-year curriculum includes two semesters totaling 29 credits, with required courses such as civil procedure, criminal law, constitutional law, torts, contracts, and legal research/writing. Grades are earned primarily through a single final examination in each course, and these grades are considered highly important to law-school success. First year grades are crucial for perceived success, largely determining which students will be invited to membership of law journal staffs, and which ones will obtain job interviews with prestigious law firms in the second year. Finally, first year grades are normalized by a grade curve, a common practice among American law schools. We note, however, that FSU requires grade distributions in the $\mathrm{D}$ range as well as for the higher grades, a practice that is less typical and may have a differential impact on students.
} 
includes required Ds in all first year sections. Thus, to find the same pattern of effects in LS2 would support the idea that the problems observed in study 1 are not particular to LS1, but instead, may perhaps be generalized to other law schools in the United States.

The time 1 assessment occurred in September of 2002. Students were encouraged to complete the survey during the first several days of the term, by a professor who visited each of the first year sections toward the end of the class hour. Students could complete the survey immediately after class, or complete and turn it in within a day of the administration. Participation counted toward the required PLP program participation, and, as in study 1 , students were offered the further incentive of a personalized report of the ultimate findings of the study.

Out of 339 matriculating students, two hundred and fifty-five students completed the time 1 survey, 113 men and 142 women. Of these, $88 \%$ were Caucasian, 3\% were African-American, 2\% were Hispanic, 4\% were Asian, and 3\% were "other". One hundred and forty-two were 25 years old or less, 56 were in the 26-30 range, 25 were in the 31-35 range, 17 were in the 36-40 range, 8 were in the $41-45$ range, 4 were in the 46-50 range, and 2 were in the 51-55 range. One hundred and sixteen reported having had a prior career. One hundred and sixty-five participants were enrolled in the day-school program, and 90 were enrolled in the night-school program.

The time 2 assessment occurred in April of 2003, again conducted by a professor visiting various class sections and encouraging students to complete the survey after class. One hundred and fifty-eight of the original participants completed the second questionnaire (attrition issues will be addressed in the results section). In our analyses below we focus on these 158 participants.

\section{Measures}

All measures were given with the same numerical scales as employed in study 1 . As in study 1, we employed the PANAS (Watson et al., 1988) and the Satisfaction with Life Scale (Diener et al., 1985) to assess SWB. To assess values (i.e. the "what" of motivation), we again employed the Aspirations Index (Kasser \& Ryan, 1996). Relative intrinsic value orientation scores were computed for each time by subtracting the sum of the three extrinsic value scores from the sum of the three intrinsic value scores. In addition, we present data on each of the six value scores separately. To assess students' reasons for being in law school (i.e. the "why" of motivation), we took a somewhat more efficient approach than in study 1. Rather than asking participants to list five law-school goals and rate their reasons for pursuing each goal, we instead asked participants to directly rate their reasons for attending the law program, using the same four reasons as described in study 1 (external, introjected, identified, and intrinsic). At time 1 they rated why they were entering the program, and at time 2, they rated why they would be returning for the second year of the program. As in study 1, a relative self-determination score was computed at each time, by subtracting the external and introjected ratings from the identified and intrinsic ratings. Finally, participants reported their LSAT scores. These scores ranged from 122 to 180 , with a median of 151 (16 participants did not report their LSAT scores). 


\section{RESULTS}

\section{Attrition}

As a first analysis, we compared the 158 participants who completed both surveys with the 97 participants who only completed the first survey, using matched-group $t$-tests. No significant differences were found between the two groups for positive affect, negative affect, life satisfaction, aggregate SWB, relative self-determination, or relative intrinsic value orientation. In addition, there was no group difference on LSAT scores (all $p s>0.10$ ). These analyses suggest that the sub-sample completing both surveys was an unbiased representation of the entire time 1 sample.

\section{Hypothesis Tests}

\section{Changes in Well-Being, Values, and Motivation}

Table 5 contains the time 1 and time 2 scores for the primary study variables, as well as the results of paired-sample $t$-tests comparing these means. As can be seen, the students evidenced strong declines in positive affect, life satisfaction, and aggregate SWB, as well as strong increases in negative affect. These effects replicate those of study 1 , and were again unmoderated by gender, age, or ethnicity.

In addition, students evidenced strong declines in self-determined motivation for attending law school. Supplementary analyses revealed that this change was primarily driven by very strong increases in students' introjected motivation for being in law school, i.e. their sense of being motivated by guilt and anxiety. In

Table 5. Study 2: Changes in well-being, values, and motivation from August 2002 to March 2003

\begin{tabular}{lccc}
\hline & \multicolumn{2}{c}{ Time } & \\
\cline { 2 - 3 } Variables & August & March & p-level for the difference \\
\hline Well-being & & & \\
$\quad$ Aggregate SWB & 4.90 & 4.11 & $<0.01$ \\
Positive affect & 3.76 & 3.40 & $<0.01$ \\
Negative affect & 2.37 & 2.61 & $<0.01$ \\
Life satisfaction & 3.51 & 3.32 & $<0.01$ \\
Values & & & 0.42 \\
Relative intrinsic value orientation & 5.17 & 5.06 & 0.50 \\
Financial success (E) & 3.18 & 3.15 & 0.01 \\
Appealing appearance (E) & 2.18 & 2.30 & 0.09 \\
Social popularity (E) & 2.27 & 2.19 & 0.49 \\
Community contribution (I) & 3.85 & 3.82 & 0.18 \\
Personal growth (I) & 4.42 & 4.37 & 0.62 \\
Emotional intimacy (I) & 4.53 & 4.51 & $<0.01$ \\
Motivation for law school & & & 0.89 \\
Relative self-determination & 5.04 & 3.78 & $<0.01$ \\
External motivation (C) & 1.64 & 1.63 & $<0.05$ \\
Introjected motivation (C) & 1.35 & 2.56 & $<0.01$ \\
Identified motivation (A) & 3.99 & 4.20 & \\
Intrinsic motivation (A) & 4.04 & 3.76 & \\
\hline
\end{tabular}

$\mathrm{E}=$ extrinsic value, $\mathrm{I}=$ intrinsic value, $\mathrm{C}=$ controlled motivation, $\mathrm{A}=$ autonomous motivation. 
addition, students reported significantly less intrinsic motivation at time 2 compared with time 1 , i.e. less sense of being motivated by enjoyment and interest. Unlike study 1 , students also reported somewhat more identified motivation at time 2 than at time 1, i.e. a sense that the goal is personally important to them. These effects were unmoderated by age, gender, or ethnicity.

Finally, examination of the six values domains revealed one significant change: as in study 1, participants evidenced a shift towards greater appearance and image values. ${ }^{4}$ The second value shift observed in study 1 , a decline in community values, was not replicated in study 2 (although the means were in the same direction), and hence the overall change in relative intrinsic value orientation was not significant in study 2 .

\section{Comparing Change Across the Two Law Schools}

We also combined the study 1 and study 2 files, then performed analyses comparing the two law schools, both in their initial levels of SWB and values, and in their relative levels of change in these variables. In other words, we tested whether the patterns of means reported in Tables 3 and 5 differed from each other.

Interestingly, only one time 1 mean differed between the two schools; LS2 students reported significantly less valuing of emotional intimacy. More importantly, mixed-model ANOVAs with school (LS1 versus LS2) as a between-participants factor and time of assessment (beginning of first year versus end of first year) as a within-participants factor revealed no two-way interactions for any of the variables included in both Tables 3 and 5 (all ps $>0.10$ ). Thus, although the means in Table 5 might appear to suggest that the second school declined less in some SWB or value measures, these apparent differences are not significant. Furthermore, the difference in the decline in the aggregate relative intrinsic value orientation measure between the two samples was non-significant.

\section{Associations of Changes in Values and Motivation with Changes in Well-Being}

Next, we tested our second hypothesis, that negative motivation and value changes in the LS2 sample would be associated with negative well-being changes in this sample. We did this in the same way as in study 1 , by first computing three difference scores (time 2 SWB minus time 1 SWB, time 2 self-determination minus time 1 self-determination, and time 2 intrinsic value orientation minus time 1 intrinsic value orientation), then correlating the value and motivation difference scores with the SWB difference score. Replicating the study 1 results, these analyses revealed that reductions in self-determination were correlated with reductions in SWB $(r=0.28, p<0.01)$, as were reductions in intrinsic value orientation $(r=0.31$, $p<0.01)$. These effects were unmoderated by age, gender, or ethnicity.

\footnotetext{
${ }^{4}$ We note that the increase in image values observed in both samples is consistent with the exceptionally high levels of interpersonal sensitivity (defined as the need to compare one's self to others) reported among lawyers in the past (i.e. Beck et al., 1995, found that $36 \%$ of attorneys were in the "clinical" range on this measure of emotional distress).
} 


\section{BRIEF DISCUSSION}

Study 2 replicated all of the study 1 results concerning declines in well-beingspecifically, students reported less aggregate SWB, positive affect, life-satisfaction, and more negative affect at time 2 compared with time 1 . Study 2 also replicated the overall decline in self-determined motivation for law school, although the pattern was somewhat different from study 1 concerning the four particular reasons measured. This may reflect that fact that, in order to simplify administration of the survey, in study 2 we directly assessed students' motivations for entering law school, rather than requiring students to generate personal goals as in study 1 . Furthermore, study 2 replicated the increase in appearance values seen in study 1 . Although study 2 did not replicate the significant decline in community values or the decline in relative intrinsic valuing observed in study 1, supplementary analyses revealed that there was no significant difference between the LS1 and LS2 samples in the degree of decline in these variables. Finally, study 2 replicated the study 1 associations between negative value changes and negative well-being changes, and between negative motivation changes and negative well-being changes.

\section{GENERAL DISCUSSION}

In this research we sought to conceptually replicate prior studies showing declines in well-being and increases in depression by new law students (Benjamin et al., 1986). In addition, we hoped to shed new light on the potential causes of any well-being changes found, as past work has focused primarily on describing or documenting negative change, rather than using theory to explain it (Dammeyer \& Nunez, 1999). Specifically, we applied measures from the self-determination theory of optimal motivation (Deci \& Ryan, 1985, 1991, 2000) to assess whether students evidence negative changes in their motives or values during the first year of law school (Krieger, 1998). Consistent with the concerns of various legal scholars regarding excessive performance and grading pressures in legal education, we hypothesized that shifts away from intrinsic motives and values, and towards more extrinsic motives and values, might occur in our sample.

To summarize the study 1 results: Preliminary analyses revealed that at time 1 the law students were higher in SWB than the comparison sample (advanced undergraduates), and also had more intrinsic values. These data suggest that law students are relatively "normal" at the outset, rather than being an especially unhappy or materialistic population. A second preliminary analysis showed that time 1 selfdetermined motivations and intrinsic values in the law student sample correlated positively with their time 1 SWB. These cross-sectional data establish that the law students are similar to past samples studied by SDT researchers. A third preliminary analysis found that students evidenced large declines in positive affect and lifesatisfaction, and large increases in negative affect, depression, and physical symptomology, from the beginning to the end of their first year of law school. These data establish that these law students were similar, in terms of declining SWB, to past law student samples (Benjamin et al., 1986).

What was the cause of the precipitous decline in well being during the first year? Although the answer to this question is doubtless multi-factorial, the data obtained 
from our measures of motivation and values suggest some possible answers. In testing our first primary hypothesis, we found that students declined in their endorsement of intrinsic values over the first year, specifically moving away from community service values and moving towards appearance and image values. In addition, students felt less self-determined in their law school goals by the end of the year, specifically pursuing their goals less for reasons of interest and enjoyment, and more for reasons of pleasing or impressing others. These two findings support the supposition that law school may bring about some negative changes in student motivations and values. Our second primary hypothesis test found significant correlations between the changes in motivation and values and the changes in SWB, consistent with the proposition that motivational changes may help explain the SWB changes. Of course, causality cannot be definitively established with these correlational data.

We also conducted several sets of supplementary analyses in study 1 . The first set examined the stability of the time 1/time 2 changes at two later survey administrations. We found that neither the losses in SWB nor in relative intrinsic value orientation rebounded at either time 3 or time 4 : that is, there were no significant changes from time 2 to time 3, or from time 3 to time 4, in these measures.

Our second set of supplementary analyses examined predictors of GPA. These data revealed that positive motivation uniquely predicted greater grade attainment during the first semester of law school, even controlling for each student's LSAT score (which was also significant). This finding is consistent with much previous self-determination theory research, which indicates that people perform more persistently, flexibly, creatively, and effectively when they act for intrinsic and self-determined reasons (Ryan et al., 1996; Deci \& Ryan, 2000).

However, there was also a potential irony to the latter result: our third set of supplementary analyses revealed that students who attained high first semester grade-point averages in turn evidenced significant shifts towards high-stress, moneyoriented legal career preferences, and significant shifts away from more serviceoriented career preferences. Thus, although students who began with intrinsic motivations and values tended to do well academically, their high performance may potentially have some negative effects as well, in that they then tended to shift toward more lucrative, high-prestige career preferences. From the SDT perspective (and see Schiltz, 1999), the values typically associated with such careers tend to contribute to decreased health, SWB, and career satisfaction over time.

Two unpredicted study 1 findings are worthy of mention. One was the samplewide shift away from lucrative career endorsement over the first year. We had hypothesized the opposite result, given the emphasis on external rewards (grades, high pay, and prestigious careers) in many law school cultures. This sample-wide shift may reflect the fact that the mean student GPA was a $\mathrm{C}+$, considerably lower than these high-achieving university students had earned before law school. Perhaps in the face of this perceived failure, the majority of students below the top of the grade curve became discouraged about their chances of obtaining lucrative positions immediately after law school, while students who performed better might feel more capable of conforming to the prevailing values regarding prestige and high-paying careers (in fact, the higher-paying law firms do primarily recruit from the top of each law school class). Supporting the latter idea, the correlational analyses reported in study 1 demonstrated that students with higher grades did in fact shift towards more 
lucrative legal careers (while those with lower grades shifted in the opposite direction). However, this idea obviously requires further study.

The second unpredicted finding in study 1 was that, whereas we had expected a continued shift away from intrinsic and towards extrinsic values between times 2 and 3, we discovered instead that essentially all types of valuing had decreased between the end of the first year and the middle of the second year, a pattern that was maintained at time 4 . However, this data appears consistent with previous reports of law-student disengagement from their studies in the second and third years of school (Fines, 1997; Anonymous, 1998; Glesner, 1991; Granfield, 1992; Gulati, Sander, \& Sockloskie, 2001), and of a general "numbing" of values and emotions by excessively analytical legal processes (Sells, 1994). The finding also appears consistent with the common stereotype that lawyers "have no values" that they are hired guns willing to represent any position that promises to pay. Obviously, however, this issue also requires further study.

Study 2, which addressed a sample of first-year students from a very different law school, replicated almost all of the important findings of study 1: students again evidenced negative changes in every measure of well-being as well as negative changes in felt self-determination, i.e. the "why" of motivation. Also, LS2 students manifested a significant increase in appearance values. However, the study 2 sample did not evidence a significant decrease in community valuing. We note here that the failure to replicate this effect found in the LS1 sample may result from the fact that students at LS2 were significantly older on average than the LS1 sample, and many are part-time students. Perhaps as a result, the LS2 students were more stable and better integrated into the broader community, enabling them to avoid the decline in community values. The existence of a mandatory grade curve at LS1 may also have more negatively impacted the values of that sample, as such curves create more competition at the expense of cooperation and community (Fines, 1997). Certainly these speculations require further study, but we note that the consistency of the other results between the two samples (including a complete lack of sample by time interactions), despite the many manifest differences in the schools, supports the generalizability of the overall pattern.

\section{Limitations and Directions for Future Research}

Several study limitations are worthy of mention. First, we examined only two samples of law students. Although the two institutions studied differed in a number of ways, further research is necessary to establish the generalizability of the effects to other schools. Such research on a larger number of law schools, with a range of institutional values, grading systems and programmatic/instructional emphases, might begin to identify particular pedagogical and contextual factors that aggravate or ameliorate the effects observed in our study. Second, we did not conduct longitudinal studies of other beginning professional students, such as those in medical or business schools. While past work has found that law students experience significantly greater emotional distress than medical students (Shanfield \& Benjamin, 1985; Kellner, Wiggins, \& Pathak, 1986; Benjamin et al., 1986), it may be that the changes documented here would also occur in other taxing post-graduate programs. We believe that, if future research does find similar changes in other professional 
students, this does not mean that the negative effects in law students should be ignored; instead, it may be indicative of more pervasive problems in American professional education that should be broadly addressed. Third, in this initial study we have not attempted to determine which particular aspects of legal education may be problematic. In other words, while these studies are new in documenting negative changes in motivation and values (as well as replicating earlier findings regarding well-being), they do not show which specific features of the law-school environment may have produced these changes. Further research that seeks to correlate the motivation and value measures with specific aspects of legal education will be instructive in this regard. Fourth, it would be useful to track students not only through all three years of law school, but also into their careers, to see (i) if the data replicate previous findings of long-term negative effects (Benjamin et al., 1986) and (ii) whether specific course/program choices, law-school environments, or career choices correlate with changes in values, motivation, or well-being.

\section{Conclusion}

Past scholarly commentaries and previous studies paint a bleak picture of the effects of legal education on the well-being of law students. Our data from two very diverse law schools confirms these negative reports, and further reveals that in these classes, the law-school experience was associated with troubling increases in extrinsic values and declines in self-determined motivation. If these experiences are common in American law schools, as anecdotal reports and other studies indicate, it would suggest that various problems reported in the legal profession, such as depression, excessive commercialism and image-consciousness, and lack of ethical and moral behavior, may have significant roots in the law-school experience.

\section{APPENDIX}

Methodology and list used to assess career preferences in all three surveys in study 1 . Also presented are our a priori classifications of careers as either money $(M)$, service $(\mathrm{S})$, or other $(\mathrm{O})$.

Current Career Inclination: Below are fifteen law career positions. Assume that you could have any of these positions/careers for your first 8 years after graduation from law school, and also assume that any college loan obligations you might have would be handled by your choice. Select the 3 positions which you would most likely prefer, in rank order, by writing " 1 ,", " 2 ," or " 3 " in the appropriate space. Leave the other 12 spaces blank. In making your choices, do not be concerned that some of the positions may overlap, or that your real first preference may not be listed.

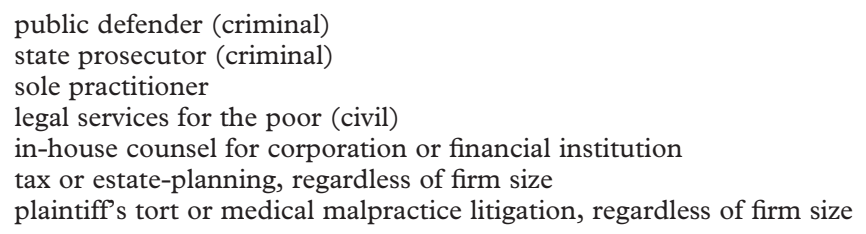


$O$ general practice or family law, regardless of firm size

$M \quad$ corporate/commercial law, regardless of firm size

$O$ business person (not practicing law)

$O$ elected government official (not practicing law)

$O \quad$ small firm practice

$M \quad$ large firm practice

$S \quad$ public agency lawyer

$S \quad$ counsel for nonprofit organization

\section{REFERENCES}

Allen, R. B. (1997). Alcoholism, drug abuse and lawyers: Are we ready to address the denial? Creighton Law Review, 31, 265-277.

American Bar Association, Section of General Practice. (1991). The report of "At the Breaking Point": A national conference on the emerging crisis in the quality of lawyers' health and lives, and its impact on law firms and client services. Chicago, IL: American Bar Association.

Anonymous. (1998). Making docile lawyers: An essay on the pacification of law students. Harvard Law Review, 111, 2027-2044.

Association of American Law Schools (AALS), The Special Committee. (1994). Report of the AALS Special Committee on problems of substance abuse in the law schools. Fournal of Legal Education, 44, 35-80.

Astin, A. (1984). Pre-law students: A national profile. Fournal of Legal Education, 73, 75-84.

Beck, A. T. (1967). Cognitive therapy and emotional disorders. New York: International Universities Press.

Beck, C. J. A., Sales, B. D., \& Benjamin, C. A. H. (1995). Lawyer distress: Alcohol-related problems and other psychological concerns among a sample of practicing lawyers. Fournal of Law and Health, 10, 1-94.

Benjamin, G. A. H., Darling, E. J., \& Sales, B. (1990). The prevalence of depression, alcohol abuse, and cocaine abuse among United States lawyers. International fournal of Law and Psychiatry, 13, 233-246.

Benjamin, G. A. H., Kaszniak, A., Sales, B., \& Shanfield, S. B. (1986). The role of legal education in producing psychological distress among law students and lawyers. American Bar Foundation Research fournal, 225-252.

Burnett, C. A. (1998). 8/11/98 interview with L. Krieger. National Institute for Occupational Safety and Health, Cincinnati, OH.

Coquillette, D. R. (1994). Professionalism: The deep theory. North Carolina Law Review, 72, 1271-1277.

Culp, D. R. (1994). Law school: A mortuary for poets and moral reason. Campbell Law Review, 16, 61101.

Daicoff, S. (1997). Lawyer know thyself: A review of empirical research on attorney attributes bearing on professionalism. American University Law Review, 46, 1337-1428.

Dammeyer, M. M., \& Nunez, N. (1999). Anxiety and depression among law students: Current knowledge and future directions. Law and Human Behavior, 23, 55-73.

Deci, E. L. (1972). Intrinsic motivation, extrinsic reinforcement, and inequity. Fournal of Personality and Social Psychology, 22, 113-120.

Deci, E. L. (1975). Intrinsic motivation. New York: Plenum.

Deci, E. L., Koestner, R., \& Ryan, R. M. (1999). A meta-analytic review of experiments examining the effects of extrinsic rewards on intrinsic motivation. Psychological Bulletin, 125, 627-668.

Deci, E. L., \& Ryan, R. M. (1985). Intrinsic motivation and self-determination in human behavior. New York: Plenum.

Deci, E. L., \& Ryan, R. M. (1991). A motivational approach to self: Integration in personality. In R. Dienstbier (Ed.), Nebraska symposium on motivation: Perspectives on motivation (Vol. 38, pp. 237-288). Lincoln, NE: University of Nebraska Press.

Deci, E. L., \& Ryan, R. M. (2000). The "what" and "why" of goal pursuits: Human needs and the selfdetermination of behavior. Psychological Inquiry, 11, 227-268.

Diener, E. (1984). Subjective well-being. Psychological Bulletin, 95, 542-575.

Diener, E. (1994). Assessing subjective well-being: Progress and opportunities. Social Indicators Research, 31, 103-157.

Diener, E., Emmons, R., Larsen, R., \& Griffin, S. (1985). The Satisfaction with Life Scale. Fournal of Personality Assessment, 47, 1105-1117.

Diener, E., \& Lucas, R. E. (1999). Personality and subjective well-being. In D. Kahneman, E. Diener, \& N. Schwarz (Eds.), Well-being: The foundations of hedonic psychology (pp. 213-229). New York: Sage.

Drogen, E. (1991). Alcoholism in the legal profession: Psychological and legal perspectives and interventions. Law and Psychology Review, 15, 117-162. 
Eaton, W., Anthony, J., Mandel, W., \& Garrision, R. (1990). Occupations and the prevalence of major depressive disorder. Fournal of Occupational Medicine, 32, 1079-1087.

Emmons, R. A. (1991). Personal strivings, daily life events, and psychological and physical well-being. fournal of Personality, 59, 453-472.

Emmons, R. A. (1999). The psychology of ultimate concerns: Motivation and spirituality in personality. New York: Guilford.

Fines, B. G. (1997). Competition and the curve. University of Missouri-Kansas City Law Review, 65, 879-915.

Glesner, B. A. (1991). Fear and loathing in the law schools. Connecticut Law Review, 23, 627-668.

Granfield, R. (1992). Making elite lawyers. New York: Routledge.

Gulati, M., Sander, R., \& Sockloskie, R. (2001). The happy charade: An empirical examination of the third year of law school. Fournal of Legal Education, 51, 235-266.

Halpern, S. C. (1982). On the politics and pathology of legal education (or, whatever happened to that blindfolded lady with the scales?). Fournal of Legal Education, 32, 383-394.

Hess, G. F. (2002). Heads and hearts: The teaching and learning environment in law school. fournal of Legal Education, 52, 75-111.

Janoff, S. (1991). The influence of legal education on moral reasoning. Minnesota Law Review, 76, 325331.

Joy, P. A. (1994). What we talk about when we talk about professionalism: A review of lawyers' ideals/ lawyers' practices. Georgetown Fournal of Legal Ethics, 987, 1007-1008.

Kasser, T., \& Ryan, R. M. (1993). A dark side of the American dream: Correlates of financial success as a central life aspiration. Fournal of Personality and Social Psychology, 65, 410-422.

Kasser, T., \& Ryan, R. M. (1996). Further examining the American dream: Well-being correlates of intrinsic and extrinsic goals. Personality and Social Psychology Bulletin, 22, 281-288.

Kellner, R., Wiggins, R., \& Pathak, D. (1986). Distress in medical and law students. Comprehensive Psychiatry, 27, 220-223.

Kennedy, D. (1982). Legal education and the reproduction of hierarchy. Fournal of Legal Education, 32, 591-615.

Krieger, L. S. (1998). What we're not telling law students - and lawyers - that they really need to know: Some thoughts-in-acting toward revitalizing the profession from its roots. Fournal of Law and Health, 13, $1-48$.

Kronman, A. T. (1993). The lost lawyer: Failing ideals of the legal profession. Cambridge: Belknap Press of Harvard University Press.

Linowitz, S. M. (1994). The betrayed profession: Lawyering at the end of the twentieth century. New York: Scribner's.

Little, B. R. (1993). Personal projects and the distributed self: Aspects of a conative psychology. In J. Suls (Ed.), The self in social perspective: Psychological Perspectives on the self (Vol. 4, pp. 157-185). Hillsdale, NJ: L. Erlbaum.

Lykken, D., \& Tellegen, A. (1996). Happiness is a stochastic phenomenon. Psychological Science, 7, $186-189$.

Maslow, A. H. (1970). Motivation and personality. New York: Harper and Row.

Meltsner, M. (1983). Feeling like a lawyer. Fournal of Legal Education, 33, 624-635.

Mixon, J., \& Schuwerk, R. P. (1995). Personal dimension of professional responsibility. Law and Contemporary Problems, 58, 87-115.

Roach, C. A. (1994). A river runs through it: Tapping into the informational stream to move students from isolation to autonomy. Arizona Law Review, 36, 667-699.

Ryan, R. M., \& Connell, J. P. (1989). Perceived locus of causality and internalization: Examining reasons for acting in two domains. Fournal of Personality and Social Psychology, 57, 749-761.

Ryan, R. M., Sheldon, K. M., Kasser, T., \& Deci, E. (1996). All goals were not created equal: An organismic perspective on the nature of goals and their regulation. In P. M. Gollwitzer, \& J. A. Bargh (Eds.), The psychology of action: Linking motivation and cognition to behavior (pp. 7-26). New York: Guilford.

Schiltz, P. J. (1999). On being a happy, healthy, and ethical member of an unhappy, unhealthy, and unethical profession. Vanderbilt Law Review, 52, 871-951.

Sells, B. (1994). The soul of the law. Rockport, MA: Element.

Shanfield, S. B., \& Benjamin, G. A. H. (1985). Psychiatric distress in law students. Fournal of Legal Education, 35, 65-75.

Sheldon, K. M., Arndt, J., \& Houser-Marko, L. (2003a). In search of the organismic valuing process: The human tendency to move towards beneficial goal choices. Fournal of Personality, 71, 835-869.

Sheldon, K. M., \& Elliot, A. J. (1999). Goal striving, need-satisfaction, and longitudinal well-being: The Self-Concordance Model. Fournal of Personality and Social Psychology, 76, 482-497.

Sheldon, K. M., \& Kasser, T. (1995). Coherence and congruence: Two aspects of personality integration. fournal of Personality and Social Psychology, 68, 531-543. 
Sheldon, K. M., \& Kasser, T. (1998). Pursuing personal goals: Skills enable progress, but not all progress is beneficial. Personality and Social Psychology Bulletin, 24, 1319-1331.

Sheldon, K. M., \& Kasser, T. (2001). Getting older, getting better? Personal strivings and psychological maturity across the life span. Developmental Psychology, 37, 491-501.

Sheldon, K. M., \& McGregor, H. (2000). Extrinsic Value Orientation and the "tragedy of the commons." Fournal of Personality, 68, 383-411.

Sheldon, K. M., Ryan, R. M., Deci, E. L., \& Kasser, T. (in press). The independent effects of goal contents and motives on well-being: It's both what you pursue and why you pursue it. Personality and Social Psychology Bulletin.

Sheldon, K. M., Sheldon, M. S., \& Osbaldiston, R. (2000). Prosocial values and group-assortation within an $N$-person prisoner's dilemma. Human Nature, 11, 387-404.

Sheldon, K. M., Williams, G., \& Joiner, T. (2003b). Applying self-determination theory in the clinic: Motivating physical and mental health. New Haven, CT: Yale University Press.

Stover, R. V., \& Erlanger, H. S. (1989). Making it and breaking it. Urbana-Champaign, IL: University of Illinois Press.

Taylor, J. B. (1975). Law school stress and the "deformation professionelle". Fournal of Legal Education, 27, 251-267.

Watson, A. S. (1968). The quest for professional competence: Psychological aspects of legal education. Cincinnati Law Review, 37, 93-166.

Watson, D., Tellegen, A., \& Clark, L. (1988). Development and validation of brief measures of positive and negative affect: The PANAS scales. Fournal of Personality and Social Psychology, 54, 1063-1070. 
Copyright of Behavioral Sciences \& the Law is the property of John Wiley \& Sons Inc. and its content may not be copied or emailed to multiple sites or posted to a listserv without the copyright holder's express written permission. However, users may print, download, or email articles for individual use. 